\title{
Ombitasvir/paritaprevir/ritonavir+dasabuvir and ribavirin associated drug-induced liver injury and syndrome of inappropriate secretion of anti-diuretic hormone: A case report
}

\author{
Rahul Kumar, John Chen Hsiang, Jessica Tan, and Prem Harichander Thurairajah \\ Department of Gastroenterology and Hepatology, Changi General Hospital, Singapore
}

Dear Editor,

Treatment of hepatitis C (HCV) has changed rapidly over the course of the last 5 years with the introduction of direct antiviral agents (DAAs). DAAs are extremely potent, well tolerated and have fewer adverse reactions compared to the pegylated interferon-based treatment. Currently, there are multiple DAAs approved for treatment of chronic hepatitis $C$, depending on the genotype of HCV. Genotype 1 HCV historically has been most difficult to cure with interferon-based therapies, with cure rates of around $50 \%$.

Ombitasvir/paritaprevir/ritonavir+dasabuvir (Viekira Pak [VP] ${ }^{\circledR}$; Abbvie, Lake Bluff, IL, USA) is a fixed-dose combination of 3 DAAs, ritonavir-boosted paritaprevir, ombitasvir, and dasabuvir. A 12-week regimen with or without ribavirin for treatment of HCV genotype 1 was approved by US Food and Drug Administration in 2014 and has cure rates of $>95 \%$ in clinical trials. ${ }^{2,3}$ VP is thus an accepted treatment option for genotype $1 \mathrm{HCV}$ infection by both the American and European Societies of the Study of Liver Diseases. ${ }^{4,5}$

The safety and efficacy of VP are well-established. The common side effects include a headache, fatigue, nausea, pruritus, and in- somnia, reported in up to $>10 \%$ of subjects. Rare cases of hepatotoxicity $(<1 \%)$ are reported in patients with advanced cirrhosis. ${ }^{3}$

In the post-marketing surveillance angioedema, erythema multiforme and drug-induced pneumonitis have been reported so far. $^{6,7}$

We present a case of an Asian, Malay male with HCV-induced compensated liver cirrhosis who developed the syndrome of inappropriate secretion of anti-diuretic hormone (SIADH) and drug-induced liver injury (DILI) following treatment with VP+ribavirin.

\section{CASE PRESENTATION}

A 54-year-old Malay, male patient was diagnosed to have HCV genotype 1a on routine health screening in 2003. The likely source of HCV acquisition was intravenous drug use. The patient had also frequently abused alcohol in the past but has been abstinent for the last 2 years. His other co-morbidities included hypertension and hyperlipidemia. His regular medications included aspirin, bisoprolol, enalapril, nifedipine, omeprazole, and simvastatin.

\footnotetext{
Abbreviations:

$A D R$, adverse drug reaction; DAA, directly acting antiviral; DILI, drug induced liver injury, ED, Emergency Department; HCV, hepatitis C virus; RUCAM scale, Roussel Uclaf Causality Assessment Method (RUCAM) scale; SIADH, syndrome of inappropriate secretion of anti diuretic hormone; ULN, upper limit of normal; $V P$, Viekira Pak
}

\section{Corresponding author : Rahul Kumar}

Department of Gastroenterology and Hepatology, Changi Genera Hospital, 2 Simei Street 3, 529889, Singapore

Tel: +65-69365728, Fax: +65-62830402

E-mail: rahul_kumar@cgh.com.sg

https://orcid.org/0000-0002-5092-4821 
Further evaluation showed patient as having liver cirrhosis, based on an ultrasonography finding of coarsened parenchymal echotexture and nodular surface. There was no sonographic evidence or clinical ascites. FibroScan ${ }^{\circledR}$ (Echosens, Paris, France) showed a median liver stiffness of $75 \mathrm{kPa}$ with M-probe. An esophagogastroduodenoscopy showed three columns of small varices. He was treatment-naïve patient. There was no hepatitis $B$ virus or human immunodeficiency virus co-infection.

He was commenced on treatment with VP+ribavirin on 16 March 2017 with a pretreatment viral load of $5.13 \mathrm{log} \mathrm{IU} / \mathrm{mL}$. Simvastatin was stopped one week before initiation of VP+ribavirin as significant drug interaction was expected. ${ }^{8}$ The patient was reviewed in an outpatient clinic in week 2 and 4 of treatment and was noted to be well. Liver panel, renal panel, and full blood count were within the expected range (Table 1). HCV RNA titer at week 2 and 4 of treatment was not detectable.

At week 9 of treatment, he presented to the emergency department (ED) with complaints of bilateral lower limb weakness, cramps, and lethargy. Blood tests showed severe hyponatremia with serum sodium levels of $99 \mathrm{mmol} / \mathrm{L}$. His liver functions have worsened with increased serum bilirubin and transaminases levels. Full blood count showed lower than baseline hemoglobin. The serum marker of rhabdomyolysis such as serum creatine kinase levels and serum aldolase levels were increased seven times the upper limit of normal (ULN) and two times the ULN, respectively. The patient was euvolemic and did not have increased thirst, polydipsia or any concomitant drug use; it was consistent with hypotonic hyponatremia as the calculated serum osmolarity was low.

Figure 1 illustrates the changes in serum sodium and serum creatinine levels over the course of VP and ribavirin initiation. Table 1 illustrates the specific laboratory values of the relevant tests carried out before treatment initiation, at week 4 of treatment and at presentation of clinical symptoms (week 9 of treatment).

The cause of hyponatremia was SIADH, which was diagnosed

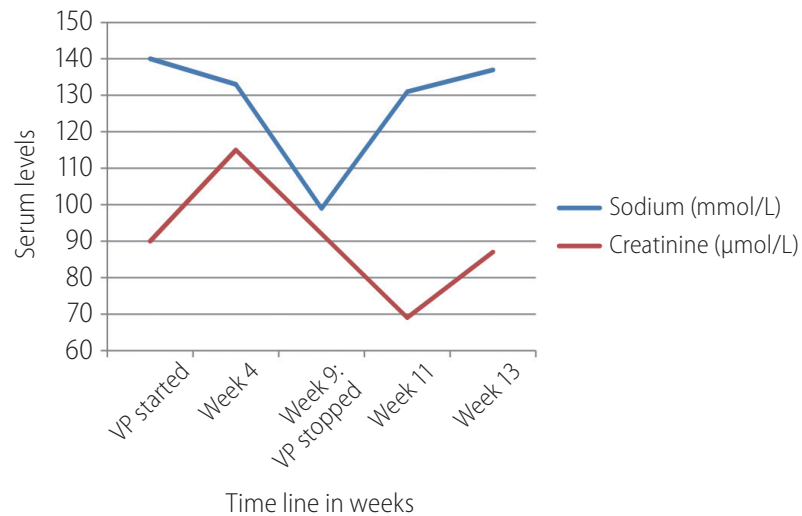

Figure 1. Changes in serum sodium and creatinine levels before, during and after treatment with Viekira Pak (VP)+ribavirin. The sodium levels dropped to $99 \mathrm{mmol} / \mathrm{L}$ in at week 9 after initiation of VP+ribavirin from pre-treatment level of $140 \mathrm{mmol} / \mathrm{L}$. Serum creatinine levels were within the normal range before, during and at presentation in emergency department at week 9 of treatment.

Table 1. Laboratory values of the relevant tests carried out before treatment initiation, at week 4 on treatment and at presentation in emergency department (ED) (week 9 of treatment)

\begin{tabular}{|c|c|c|c|c|}
\hline & Reference range & $\begin{array}{l}\text { Pre treatment } \\
\text { initiation }\end{array}$ & Week 4 & $\begin{array}{c}\text { Week } 9 \text { (at } \\
\text { presentation in ED) }\end{array}$ \\
\hline Urea (mmol/L) & $2.8-7.7$ & 3.6 & 4.9 & 6.9 \\
\hline Sodium (mmol/L) & $135-145$ & 140 & 133 & 99 \\
\hline Potassium (mmol/L) & $3.5-4.5$ & 4.5 & Not available & 3.7 \\
\hline Glucose (mmol/L) & $3.1-7.8$ & 5.5 & 3.6 & 5.7 \\
\hline Creatinine $(\mu \mathrm{mol} / \mathrm{L})$ & $65-125$ & 90 & 115 & 92 \\
\hline Albumin (g/L) & $37-51$ & 41 & 43 & 41 \\
\hline Bilirubin, total $(\mu \mathrm{mol} / \mathrm{L})$ & $5.0-30.0$ & 8.9 & 37.9 & 88.4 \\
\hline Alkaline phosphatase $(\mathrm{U} / \mathrm{L})$ & $32-103$ & 114 & 89 & 79 \\
\hline Alanine transaminases $(\mathrm{U} / \mathrm{L})$ & $10-55$ & 134 & 39 & 424 \\
\hline Aspartate transaminases $(\mathrm{U} / \mathrm{L})$ & $10-45$ & 88 & 43 & 284 \\
\hline Prothrombin time (sec) & $9.5-11.5$ & 11.6 & 11.3 & 11.4 \\
\hline Hemoglobin (g/dL) & $13.0-17.0$ & 14.1 & 14.2 & 11.4 \\
\hline Platelet count $\left(\times 10^{3} / \mu \mathrm{L}\right)$ & $150-450$ & 110 & 148 & 194 \\
\hline
\end{tabular}


based on blood and urine laboratory parameters (Serum sodium: $99 \mathrm{mmol} / \mathrm{L}$, Serum osmolality: $223 \mathrm{mOsm} / \mathrm{kg}$, Urinary sodium: 46 $\mathrm{mmol} / \mathrm{L}$, Urinary osmolality: $562 \mathrm{mOsm} / \mathrm{kg}$. Normal levels of thyroxine, thyroid stimulating hormone and serum 8 am cortisol).

Computerized tomography scans of brain and thorax to look for common causes of SIADH were negative for any possible etiologies in the brain or thorax.

There was no precipitating factor for liver injury and SIADH, apart from initiation of $\mathrm{VP}+$ ribavirin, which was discontinued on

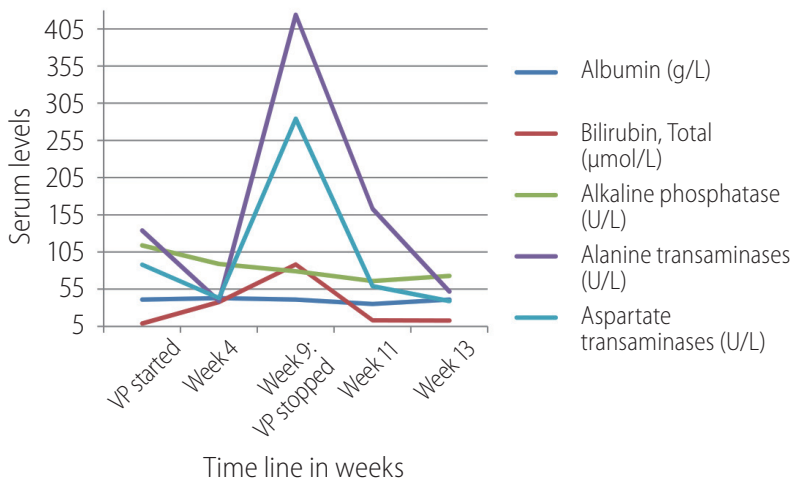

Figure 2. Changes in serum levels of components of liver function tests before, during and after treatment with Viekira Pak (VP)+ribavirin combination. There was more than 10 fold rise in alanine transaminases and aspartate transaminases levels at week 9, compared to week 4 on treatment. Serum total bilirubin levels also rose to more than 10 fold from pre-treatment levels. presentation.

DILI was suspected based on the relative derangement of liver functions compared to the baseline values. An ultrasound doppler study of the portal and hepatic circulation did not reveal any abnormality except known cirrhosis. There were no hypotensive episodes. New drugs had not been started after HCV treatment.

The patient was diagnosed as having DILI and SIADH secondary to treatment of VP+ribavirin combination. He was conservatively treated with water restriction and salt tablets. He recovered over the course of the next two weeks and was discharged well. Laboratory parameters returned to normal after four weeks of discontinuation of VP+ribavirin therapy, which was illustrated in Figure 2. The specific laboratory values at clinical presentation in ED at week 9 of treatment and at week 2 and 4 after discontinuation of VP+ribavirin therapy was illustrated in Table 2.

Even though the patient received treatment of $\mathrm{VP}+$ ribavirin combination for 8.2 weeks, he achieved a sustained virological response at 12 weeks after treatment.

\section{DISCUSSION}

Using the adverse drug reaction (ADR) probability algorithm of Naranjo et al. ${ }^{9}$ VP was determined to be the probable cause of hyponatremia. There was a temporal relationship between initia-

Table 2. Laboratory values of the relevant tests carried out at presentation in emergency department (ED), on week 2 and week 4 after discontinuation of Viekira Pak (VP)+ribavirin

\begin{tabular}{lcccc}
\hline & Reference range & $\begin{array}{c}\text { Week } \mathbf{9} \text { (at } \\
\text { presentation in ED) }\end{array}$ & $\begin{array}{c}\text { 2 weeks after } \\
\text { discontinuation of } \\
\text { VP+ribavirin }\end{array}$ & $\begin{array}{c}\text { 4 weeks after } \\
\text { discontinuation of } \\
\text { VP+ribavirin }\end{array}$ \\
\hline Urea $(\mathrm{mmol} / \mathrm{L})$ & $2.8-7.7$ & 6.9 & 4.3 & 4.1 \\
\hline Sodium $(\mathrm{mmol} / \mathrm{L})$ & $135-145$ & 99 & 131 & 137 \\
\hline Potassium $(\mathrm{mmol} / \mathrm{L})$ & $3.5-4.5$ & 3.7 & 4.0 & 5.0 \\
\hline Glucose $(\mathrm{mmol} / \mathrm{L})$ & $3.1-7.8$ & 5.7 & 7.5 & 5.1 \\
\hline Creatinine $(\mu \mathrm{mol} / \mathrm{L})$ & $65-125$ & 92 & 69 & 87 \\
\hline Albumin $(\mathrm{g} / \mathrm{L})$ & $37-51$ & 41 & 35 & 41 \\
\hline Bilirubin, Total $(\mu \mathrm{mol} / \mathrm{L})$ & $5.0-30.0$ & 88.4 & 13.2 & 12.9 \\
\hline Alkaline phosphatase $(\mathrm{U} / \mathrm{L})$ & $32-103$ & 79 & 66 & 73 \\
\hline Alanine transaminases $(\mathrm{U} / \mathrm{L})$ & $10-55$ & 424 & 163 & 52 \\
\hline Aspartate transaminases $(\mathrm{U} / \mathrm{L})$ & $10-45$ & 284 & 59 & 39 \\
\hline Prothrombin time $(\mathrm{sec})$ & $9.5-11.5$ & 11.4 & $\mathrm{NA}$ & $\mathrm{NA}$ \\
\hline Hemoglobin $(\mathrm{g} / \mathrm{dL})$ & $13.0-17.0$ & 11.4 & 13.6 & 12.5 \\
\hline Platelet count $\left(\times 10^{3} / \mu \mathrm{L}\right)$ & $150-450$ & 194 & 167 & 249 \\
\hline
\end{tabular}

NA, not available. 
tion of VP+ribavirin combination therapy and onset of symptoms and laboratory abnormalites. To the best of our knowledge, this is the first case report of VP+ribavirin therapy associated DILI and SIADH. One case of probable boceprevir-induced hyponatremia has been previously reported..$^{10}$ Boceprevir is a protease inhibitor like paritaprevir which is a component of VP combination therapy. However, the mechanism of action remains uncertain.

Distinguishing the type of hyponatremia is quite critical. In our case, the clinical picture was consistent with hypotonic hyponatremia as the calculated serum osmolarity was low (223 m0sm $/ \mathrm{kg})$. The patient was euvolumic without any clinical signs of either volume overload or volume depletion. The differential diagnosis of euvolumic hypotonic hyponatremia includes hypothyroidism, hypocortisolism, renal failure, and SIADH. The patient had no hypothyroidism, hypocortisolism, or renal failure. Thus a diagnosis of SIADH was reached.

The pathophysiologic basis of drug-induced SIADH is not entirely understood. However, the mechanism includes the drug's effect on sodium homeostasis, water homeostasis, or both. Water homeostasis can be affected by increasing levels of antidiuretic hormone, by increased production, potentiating its effect or by resetting the osmostat. There are some common medications associated with drug-induced hyponatremia and SIADH; diuretics, antidepressants, antipsychotics, anticonvulsants, and antineoplastic agents. We postulate that SIADH in this patient was related to the protease inhibitor, paritaprevir.

DILI is defined as a liver injury caused by various medications, herbs, or other xenobiotics, leading to abnormalities with the reasonable exclusion of other etiologies. It is one of the leading causes of acute liver failure worldwide. Most cases of DILI are the result of idiosyncratic metabolic responses or unexpected reactions to medication; the precise pathogenesis is poorly understood." The most widely used method for diagnosis of DILI is the Roussel Uclaf Causality Assessment Method (RUCAM) scale." Our patient scored 9 points on the RUCAM scale, where score $>8$ suggests definitive or highly probable..$^{13}$

The mechanism of DILI in our patient may in part be related to the use of simvastatin before initiation of VP+ribavirin combination and liver cirrhosis. Both of them clubbed together may have impaired liver's capacity to metabolize each drug of VP and ribavirin. Although simvastatin was stopped one week before initiation of VP+ribavirin combination, due to cirrhosis, it may not have been completely washed out from the body. A longer washout period for statins may be needed in the cirrhotic patient needing VP+ribavirin combination therapy due to potential drug interac- tions. The role of simvastatin becomes a suspect as there was a concurrent rise of serum rhabdomyolysis markers. Statin-induced rhabdomyolysis is well reported in cirrhotic as well as non-cirrhotic patients..$^{14}$ It has also been reported that a single-dose pitavastatin to cirrhotic patients with Child-Pugh class A or B resulted in a 1.19- and 2.47-fold increase in maximum concentration of the drug in plasma (Cmax) and 1.27- and 3.64-fold increase in the area under the plasma concentration-time curve from administration to last observed concentration of time (AUCt), respectively, when compared with normal subjects. ${ }^{15}$ As simvastatin and pitavastatin are the same class of drug, it's likely that similar Cmax and AUCt will be observed with simvastatin as well. Although in this patient, statins were stopped seven days before initiation of VP+ribavirin combination therapy, washout period may not be sufficient in cirrhotic patients.

In our opinion, the SIADH and DILI in this patient were associated with therapy of VP and ribavirin combination, most likely related to the protease inhibitor. Prior use of simvastatin may have played a role on the SIADH and DILI. The patient improved after discontinuation of the drug and made an uneventful recovery. Adequate washout period for statins may be required before starting protease inhibitor-containing regimen, particularly in cirrhotic patients. Further investigations will be needed to determine the mechanism of this ADR.

\section{CONCLUSION}

VP and ribavirin use in a patient with compensated cirrhosis may be associated with significant hyponatremia from SIADH and DILI; this is probably related to the use of the protease inhibitor. Further studies are required to determine the mechanistic cause of this ADR.

\section{Author's contributions}

All the authors contributed equally in the conceptualization, writing and editing of the manuscript.

\section{Conflicts of Interest}

The authors have no conflicts to disclose.

\section{REFERENCES}

1. Manns MP, McHutchison JG, Gordon SC, Rustgi VK, Shiffman M, 
Reindollar $\mathrm{R}$, et al. Peginterferon alfa-2b plus ribavirin compared with interferon alfa-2b plus ribavirin for initial treatment of chronic hepatitis C: a randomized trial. Lancet 2001;358:958-965.

2. Feld JJ, Kowdley KV, Coakley E, Sigal S, Nelson DR, Crawford D, et al. Treatment of HCV with ABT-450/r-ombitasvir and dasabuvir with ribavirin. N Engl J Med 2014;370:1594-1603.

3. Poordad F, Hezode C, Trinh R, Kowdley KV, Zeuzem S, Agarwal K, et al. ABT-460/r-ombitasvir and dasabuvir with ribavirin for hepatitis $C$ with cirrhosis. N Engl J Med 2014;370:1973-1982.

4. American Associations for the Study of Liver Diseases (AASLD). HCV guidance: recommendations for testing, managing, and treating hepatitis C. AASLD web site, <https://www.hcrguidelines.org/ treatment-naive/gt1>. Accessed 15 Jun 2018.

5. European Association for the Study of the Liver (EASL). EASL recommendations on treatment of hepatitis C 2016 Summary. EASL web site, <http://www.easl.eu/medias/cpg/HCV2016/Summary.pdf>. Accessed 15 Jun 2018.

6. Abbvie Ltd. New Zealand data sheet. New Zealand Medicines and Medical Devices Safety Authority web site, <http://www.medsafe. govt.nz/profs/datasheet/v/viekiraPaktab.pdf>. Accessed 15 Jun 2018

7. Wu SY, Faire B, Gane E. Drug-induced pneumonitis secondary to treatment with paritaprevir/ritonavir/ombitasvir and dasabuvir (VIEKIRA PAK[R]) for chronic hepatitis C: case report of an unexpected life-threatening adverse reaction. Case Rep Med 2017;2017:4895736.
8. University of Liverpool. Database of University of Liverpool. Liverpool HEP Interactions web site, <https://www.hep-druginteractions. org>. Accessed 15 Jun 2018.

9. Naranjo CA, Busto U, Sellers EM, Sandor P, Ruiz I, Roberts EA, et al. A method for estimating the probability of adverse drug reactions. Clin Pharmacol Ther 1981;30:239-245.

10. Hedrick KT, Just SM, Kahn DR. Probable boceprevir-induced hyponatremia in a patient with chronic hepatitis C. Am J Health Syst Pharm 2015;72:449-452.

11. Au JS, Navarro VJ, Rossi S. Review article: Drug-induced liver injury-its pathophysiology and evolving diagnostic tools. Aliment Pharmacol Ther 2011;34:11-20.

12. Danan G, Benichou C. Causality assessment of adverse reactions to drugs--I. A novel method based on the conclusions of international consensus meetings: application to drug-induced liver injuries. J Clin Epidemiol 1993;46:1323-1330

13. Benichou C, Danan G, Flahault A. Causality assessment of adverse reactions to drugs--II. An original model for validation of drug causality assessment methods: case reports with positive rechallenge. J Clin Epidemiol 1993;46:1331-1336.

14. Mendes P, Robles PG, Mathur S. Statin-induced rhabdomyolysis: a comprehensive review of case reports. Physiother Can 2014,66:124132.

15. Hui CK, Cheung BM, Lau GK. Pharmacokinetics of pitavastatin in subjects with Child-Pugh A and B cirrhosis. Br J Clin Pharmacol 2005;59:291-297. 